\title{
Orofacial electromyographic correlates of induced verbal
}

\section{rumination}

4 Ladislas Nalborczyk ${ }^{\mathrm{a}, \mathrm{b}, \mathrm{d}^{*}}$, Marcela Perrone-Bertolotti $^{\mathrm{a}, \mathrm{b}}$, Céline Baeyens $^{\mathrm{c}}$, Romain Grandchamp ${ }^{\mathrm{a}, \mathrm{b}}$, Mircea Polosan $^{\mathrm{e}}$, Elsa Spinelli ${ }^{\mathrm{a}, \mathrm{b}}$, Ernst H.W. Koster ${ }^{\mathrm{d}}$, Hélène Lœvenbruck ${ }^{\mathrm{a}, \mathrm{b}}$

${ }^{b}$ CNRS, LPNC UMR 5105, F-38040, Grenoble, France

$10{ }^{e}$ Univ. Grenoble Alpes, Grenoble Institut des Neurosciences, INSERM 1216, CHU de Grenoble, F-3800,0 Grenoble,

13 Disclaimer: Please note that this is an uncorrected proof that could differ from the final published 14 paper. For the final paper we refer to the published version at Biological Psychology

\footnotetext{
* Corresponding author at: Laboratoire de Psychologie \& Neurocognition (CNRS UMR 5105), BSHM, BP47 38040 Grenoble Cedex 9, France. E-mail address: ladislas.nalborczyk@ gmail.com.
} 
16 Rumination is predominantly experienced in the form of repetitive verbal thoughts. Verbal

17 rumination is a particular case of inner speech. According to the Motor Simulation view, inner

18 speech is a kind of motor action, recruiting the speech motor system. In this framework, we

19 predicted an increase in speech muscle activity during rumination as compared to rest. We also

20 predicted increased forehead activity, associated with anxiety during rumination. We measured

21 electromyographic activity over the orbicularis oris superior and inferior, frontalis and flexor

22 carpi radialis muscles. Results showed increased lip and forehead activity after rumination

23 induction compared to an initial relaxed state, together with increased self-reported levels of

24 rumination. Moreover, our data suggest that orofacial relaxation is more effective in reducing

25 rumination than non-orofacial relaxation. Altogether, these results support the hypothesis that

26 verbal rumination involves the speech motor system, and provide a promising

27 psychophysiological index to assess the presence of verbal rumination.

28 Keywords: rumination; inner speech; electromyography; orbicularis oris; frontalis; relaxation 


\section{Introduction}

As humans, we spend a considerable amount of time reflecting upon ourselves, thinking

32 about our own feelings, thoughts and behaviors. Self-reflection enables us to create and clarify

33 the meaning of past and present experiences (Boyd \& Fales, 1983; Nolen-Hoeksema, Wisco, \&

34 Lyubomirsky, 2008). However, this process can lead to unconstructive consequences when self-

35 referent thoughts become repetitive, abstract, evaluative, and self-critical (Watkins, 2008).

Indeed, rumination is most often defined as a repetitive and recursive mode of responding

37 to negative affect (Rippere, 1977) or life situations (Robinson \& Alloy, 2003). Although

38 rumination is a common process that can be observed in the general population (Watkins, 2008),

39 it has been most extensively studied in depression and anxiety. Depressive rumination has been

40 thoroughly studied by Susan Nolen-Hoeksema, who developed the Response Style Theory (RST;

41 Nolen-Hoeksema, 1991). According to the RST, depressive rumination is characterized by an

42 evaluative style of processing that involves recurrent thinking about the causes, meanings, and

43 implications of depressive symptoms. Even though rumination can involve several modalities

44 (i.e., visual, sensory), it is a predominantly verbal process (Goldwin \& Behar, 2012; McLaughlin,

45 Borkovec, \& Sibrava, 2007). In this study, we focus on verbal rumination, which can be

46 conceived of as a particularly significant form of inner speech.

47 Inner speech or covert speech can be defined as silent verbal production in one's mind or

48 the activity of silently talking to oneself (Zivin, 1979). The nature of inner speech is still a matter

49 of theoretical debate (see Perrone-Bertolotti, Rapin, Lachaux, Baciu, \& Lœvenbruck, 2014 for a

50 review). Two opposing views have been proposed in the literature: the Abstraction view and the

51 Motor Simulation view. The Abstraction view describes inner speech as unconcerned with

52 articulatory or auditory simulations and as operating on an amodal level. It has been described as

53 "condensed, abbreviated, disconnected, fragmented, and incomprehensible to others" (Vygotsky,

54 1987). It has been argued that important words or grammatical affixes may be dropped in inner 
55 speech (Vygotsky, 1987) or even that the phonological form or representation of inner words may 56 be incomplete (Sokolov, 1972; Dell \& Repka, 1992). MacKay (1992) stated that inner speech is 57 nonarticulatory and nonauditory and that "Even the lowest level units for inner speech are highly 58 abstract" (p.122).

59 In contrast with this Abstraction view, the physicalist or embodied view considers inner 60 speech production as mental simulation of overt speech production. As such, it can be viewed as 61 similar to overt speech production, except that the motor execution process is blocked and no 62 sound is produced (Grèzes \& Decety, 2001; Postma \& Noordanus, 1996). Under this Motor 63 Simulation view, a continuum exists between overt and covert speech, in line with the continuum 64 drawn by Decety and Jeannerod (1996) between imagined and actual actions. This hypothesis has 65 led certain authors to claim that inner speech by essence should share features with speech motor actions (Feinberg, 1978; Jones \& Fernyhough, 2007). The Motor Simulation view is supported by several findings. Firstly, covert and overt speech have comparable physiological correlates: for 68 instance, measurements of speaking rate (Landauer, 1962; Netsell, Ashley, \& Bakker, 2010) and 69 respiratory rate (Conrad \& Schönle, 1979) are similar in both. A prediction of the Motor 70 Simulation view is that the speech motor system should be recruited during inner speech. Subtle 71 muscle activity has been detected in the speech musculature using electromyography (EMG) 72 during verbal mental imagery, silent reading, silent recitation (Jacobson, 1931; Sokolov, 1972; 73 Livesay, Liebke, Samaras, \& Stanley, 1996; McGuigan \& Dollins, 1989), and during auditory 74 verbal hallucination in patients with schizophrenia (Rapin, Dohen, Polosan, Perrier, \& 75 Lœvenbruck, 2013). Secondly, it has been shown that covert speech production involves a similar cerebral network as that of overt speech production. Covert and overt speech both recruit essential language areas in the left hemisphere (for a review, see Perrone-Bertolotti et al., 2014).

78 However, there are differences. Consistent with the Motor Simulation view and the notion of a

79 continuum between covert and overt speech, overt speech is associated with more activity in 
80 motor and premotor areas than inner speech (e.g., Palmer et al., 2001). This can be related to the

81 absence of articulatory movements during inner verbal production. In a reciprocal way, inner

82 speech involves cerebral areas that are not activated during overt speech (Basho, Palmer, Rubio,

83 Wulfeck, \& Müller, 2007). Some of these activations (cingulate gyrus and superior rostral frontal

84 cortex) can be attributed to the inhibition of overt responses.

85 These findings suggest that the processes involved in overt speech include those required

86 for inner speech (except for inhibition). Several aphasia patient studies support this view: overt

87 speech loss can either be associated with an impairment in inner speech (e.g., Levine, Calvanio,

88 \& Popovics, 1982; Martin \& Caramazza, 1982) or with intact inner speech: only the later phases

89 of speech production (execution) being affected by the lesion (Baddeley \& Wilson, 1985;

90 Marshall, Rappaport, \& Garcia-Bunuel, 1985; Vallar \& Cappa, 1987). Geva, Bennett, Warburton,

$91 \&$ Patterson (2011) have reported a dissociation that goes against this view, however. In three

92 patients with chronic post-stroke aphasia (out of 27 patients), poorer homophone and rhyme

93 judgement performance was in fact observed in covert mode compared with overt mode. A

94 limitation of this study, though, was that the task was to detect rhymes in written words, which

95 could have been too difficult for the patients. To overcome this limitation, Langland-Hassan,

96 Faries, Richardson, \& Dietz (2015) have tested aphasia patients with a similar task, using images

97 rather than written words. They also found that most patients performed better in the overt than in

98 the covert mode. They inferred from these results that inner speech might be more demanding in

99 terms of cognitive and linguistic load, and that inner speech may be a distinct ability, with its own

100 neural substrates. We suggest an alternative interpretation to this dissociation. According to our

101 view, rhyme and homophone judgements rely on auditory representations of the stimuli (see e.g.,

102 Paulesu, Frith, \& Frackowiak, 1993). Overt speech provides a strong acoustic output that is fed

103 back to the auditory cortex and can create an auditory trace, which can be used to monitor speech.

104 In the covert mode, the auditory output is only mentally simulated, and its saliency in the 
105 auditory system is lesser than in the overt mode. This is in accordance with the finding that inner

106 speech is associated with reduced sensory cortex activation compared with overt speech (Shuster

$107 \&$ Lemieux, 2005). In patients with aphasia, the weakened saliency of covert auditory signals

108 may be accentuated for two reasons: first, because of impairment in the motor-to-auditory

109 transformation that produces the auditory simulation, and second, because of associated auditory

110 deficits. Therefore, according to our view, the reduced performance observed in rhyme and

111 homophone judgment tasks in the covert compared with the overt mode in brain-injured patients,

112 simply indicates a lower saliency of the auditory sensations evoked during inner speech

113 compared with the actual auditory sensations fed back during overt speech production. In 114 summary, these findings suggest that overt and covert speech share common subjective, 115 physiological and neural correlates, supporting the claim that inner speech is a motor simulation 116 of overt speech.

117 However, the Motor Simulation view has been challenged by several experimental results.

118 Examining the properties of errors during the production of tongue twisters, Oppenheim and Dell 119 (2010) showed that speech errors display a lexical bias in both overt and inner speech. According 120 to these researchers, errors also display a phonemic similarity effect (or articulatory bias), a 121 tendency to exchange phonemes with common articulatory features, but this second effect is only 122 observed with overt speech or with inner speech accompanied with mouthing. This has led 123 Oppenheim and Dell (2010) to claim that inner speech is fully specified at the lexical level, but 124 that it is impoverished at lower featural (articulatory) levels. This claim, related to the 125 Abstraction view, is still debated however, as a phonemic similarity effect has been found by 126 Corley, Brocklehurst and Moat (2011). Their findings suggest that inner speech is in fact 127 specified at the articulatory level, even when there is no intention to articulate words overtly. 128 Other findings however, may still challenge the Motor Simulation view. Netsell et al. (2010) have 129 examined covert and overt speech in persons who stutter (PWS) and typical speakers. They have 
130 found that PWS were faster in covert than in overt speech while typical speakers presented

131 similar overt and covert speech rates. This can be interpreted in favour of the Abstraction view, in

132 which inner representations are not fully specified at the articulatory level, which would explain

133 why they are not disrupted in PWS speech. Altogether, these results suggest that full articulatory

134 specification may not always be necessary for inner speech to be produced.

135 The aim of this study is to examine the physiological correlates of verbal rumination in an

136 attempt to provide new data in the debate between motor simulation and abstraction. A prediction

137 of the Motor Simulation view is that verbal rumination, as a kind of inner speech, should be

138 accompanied with activity in speech-related facial muscles, as well as in negative emotion or 139 anxiety-related facial muscles, but should not involve non-facial muscles (such as arm muscles).

140 Alternatively, the Abstraction view predicts that verbal rumination should be associated with an

141 increase in emotion-related facial activity, without activity in speech-related muscles and non-

142 facial muscles.

143 There is strong interest in the examination of physiological correlates of rumination as 144 traditional assessment of rumination essentially consists of self-reported measures. The 145 measurement of rumination as conceptualized by Nolen-Hoeksema (1991) was operationalized 146 by the development of the Ruminative Response Scale (RRS), which is a subscale of the response 147 style questionnaire (Nolen-Hoeksema \& Morrow, 1991). The RRS consists of 22 items that 148 describe responses to dysphoric mood that are self-focused, symptom-focused, and focused on 149 the causes and consequences of one's mood. Based on this scale, Treynor, Gonzalez \& Nolen150 Hoeksema (2003) have offered a detailed description of rumination styles and more recently; 151 Watkins $(2004,2008)$ have further characterized different modes of rumination. The validity of 152 these descriptions is nevertheless based on the hypothesis that individuals have direct and reliable 153 access to their internal states. However, self-reports increase reconstruction biases (e.g., Brewer, 
154 1986; Conway, 1990) and it is well known that participants have a very low level of awareness of

155 the cognitive processes that underlie and modulate complex behaviors (Nisbett \& Wilson, 1977).

156 In order to overcome these difficulties, some authors have attempted to quantify state

157 rumination and trait rumination more objectively, by recording physiological or neuroanatomical

158 correlates of rumination (for a review, see Siegle \& Thayer, 2003). Peripheral physiological

159 manifestations (e.g., pupil dilation, blood pressure, cardiac rhythm, cardiac variability) have been

160 examined during induced or chronic rumination. Vickers and Vogeltanz-Holm (2003) have

161 observed an increase in systolic blood pressure after rumination induction, suggesting the

162 involvement of the autonomic nervous system in rumination. Moreover, galvanic skin response

163 has shown to be increased after a rumination induction, in highly anxious women (Sigmon,

164 Dorhofer, Rohan, \& Boulard, 2000). According to Siegle and Thayer (2003), disrupted

165 autonomic activity could provide a reliable physiological correlate of rumination. In this line,

166 Key, Campbell, Bacon, and Gerin (2008) have observed a diminution of the high-frequency

167 component of heart rate variability (HF-HRV) after rumination induction in people with a low

168 tendency to ruminate (see also Woody, McGeary, \& Gibb, 2014). A consistent link between

169 perseverative cognition and decreased HRV was also found in a meta-analysis conducted by

170 Ottaviani et al. (2015). Based on these positive results and on suggestions that labial EMG

171 activity may accompany inner speech and therefore rumination, our aim was to examine facial

172 EMG as a potential correlate of rumination and HRV as an index to examine concurrent validity.

173 In addition to labial muscular activity, we also recorded forehead muscular activity (i.e.,

174 frontalis muscle) because of its implication in prototypical expression of sadness (e.g., Ekman,

175 2003; Kohler et al., 2004), reactions to unpleasant stimuli (Jäncke, Vogt, Musial, Lutz, \&

176 Kalveram, 1996), and anxiety or negative emotional state (Conrad \& Roth, 2007) ${ }^{1}$. Our

1 The corrugator supercilii was another potential site, as it is sensitive to negative emotions. However, it has been claimed to be mostly activated for strong emotions such as fear/terror, anger/rage and sadness/grief (Ekman \& Friesen, 1978; Sumitsuji, Matsumoto, Tanaka, Kashiwagi, \& Kaneko, 1967). The 
177 hypothesis was that frontalis activity could be an accurate electromyographic correlate of induced

178 rumination, as a negatively valenced mental process.

179 In this study, we were also interested in the effects of relaxation on induced rumination.

180 Using a relaxation procedure targeted on muscles involved in speech production is a further way

181 to test the reciprocity of the link between inner speech (verbal rumination) and orofacial muscle

182 activity. If verbal rumination is a kind of action, then its production should be modulated in

183 return by the effects of relaxation on speech effectors. This idea is supported by the results of

184 (among others) Cefidekhanie, Savariaux, Sato and Schwartz (2014), who have observed

185 substantial perturbations of inner speech production while participants had to realize forced 186 movements of the articulators.

187 In summary, the current study aimed at evaluating the Motor Simulation view and the

188 Abstraction view by using objective and subjective measures of verbal rumination. To test the

189 involvement of the orofacial motor system in verbal rumination, we used two basic approaches.

190 In the first approach, we induced verbal rumination and examined concurrent changes in facial

191 muscle activity (Experiment 1). In the second approach, we examined whether orofacial 192 relaxation would reduce verbal rumination levels (Experiment 2). More specifically, in

193 Experiment 1, we aimed to provide an objective assessment of verbal rumination using 194 quantitative physiological measures. Thus, we used EMG recordings of muscle activity during 195 rumination, focusing on the comparison of speech-related (i.e., two lip muscles - orbicularis oris superior and orbicularis oris inferior) and speech-unrelated (i.e., forehead -frontalis- and forearm - flexor carpi radialis) muscles. Under the Motor Simulation view, an increase in lip and

198 forehead EMG activity should be observed after rumination induction, with no change in forearm

rumination induction used in this study was designed to have participants self-reflect and brood over their failure at the IQ-test. It was not meant to induce such strong emotions. Several studies have reported increased activity in the frontalis muscle at rest in anxious or generalized anxiety disorder patients (for a review see Conrad \& Roth, 2007). We expected the type of emotional state induced by rumination to be closer to anxiety or worry than to strong emotions like fear, anger or grief. It was therefore more appropriate to record non-speech facial activity in the frontalis rather than in the corrugator. 
199 EMG activity, associated with an increase in self-reported rumination. Alternatively, under the

200 Abstraction view, an increase in forehead activity should be observed, associated with an increase

201 in self-reported rumination, and no changes in either lip or forearm activity should be noted.

202 In Experiment 2, in order to assess the reciprocity of the rumination and orofacial motor 203 activity relationship, we evaluated the effects of orofacial relaxation on rumination. More 204 specifically, we compared three kinds of relaxation: i) Orofacial Relaxation (i.e., lip muscles), ii) 205 Arm Relaxation (i.e., to differentiate effects specific to speech-related muscle relaxation) and iii) 206 Story Relaxation (i.e., to differentiate effects specific to attentional distraction). If the Motor 207 simulation view is correct, we predicted a larger decrease of lip and forehead muscle activity after 208 an Orofacial Relaxation than after an Arm Relaxation (associated with a larger decrease in self209 reported rumination), which should also be larger than after listening to a story. We also

210 predicted that forearm activity should remain stable across the three conditions (i.e., should not 211 decrease after relaxation). Alternatively, if the Abstraction view is correct, we predicted that none 212 of the relaxation conditions should have an effect on lip or arm activity, because none of these 213 should have increased after induction. However, we expected to observe a decrease in forehead 214 activity and self-reported rumination after Orofacial or Arm relaxation, this decrease being larger 215 than after listening to a Story. Importantly, we predicted that, under the Abstraction View no 216 superiority of the Orofacial relaxation should be observed over the Arm relaxation.

\section{Method}

\subsection{Participants}

Because of the higher prevalence of rumination in women than in men (see Johnson \&

221 Whisman, 2013; for a recent meta-analysis), we chose to include female participants only.

222 Seventy-two female undergraduate students from Université Grenoble Alpes, native French 223 speaking, participated in our study. One participant presenting aberrant data (probably due to 
224 inadequate sensor sticking) was removed from analyses. Final sample consisted of seventy-one

225 undergraduate female students $\left(\mathrm{M}_{\mathrm{age}}=20.58, \mathrm{SD}_{\mathrm{age}}=4.99\right)$. They were recruited by e-mail

226 diffusion lists and participated in the experiment for course credits. They did not know the goals

227 of the study. The cover story presented the research as aiming at validating a new I.Q. test, more

228 sensitive to personality profiles. Participants reported having no neurologic or psychiatric

229 medical history, no language disorder, no hearing deficit, and taking no medication. Each

230 participant gave written consent and this study has been approved by the local ethical committee

231 (CERNI, N² 2015-03-03-61).

\subsection{Material}

EMG signals were detected with Trigno ${ }^{\mathrm{TM}}$ Mini sensors (Delsys Inc.) at a sampling rate of 1926 samples/s with a band pass of $20 \mathrm{~Hz}(12 \mathrm{~dB} / \mathrm{oct})$ to $450 \mathrm{~Hz}(24 \mathrm{~dB} / \mathrm{oct})$ and were amplified by a Trigno $^{\mathrm{TM}}$ 16-channel wireless EMG system (Delsys Inc.). The sensors consisted of two $5 \mathrm{~mm}$ long, $1 \mathrm{~mm}$ wide parallel bars, spaced by $10 \mathrm{~mm}$, which were attached to the skin using double-sided adhesive interfaces. The skin was cleaned by gently scrubbing it with $70 \%$ isopropynol alcohol. EMG signals were then synchronized using the PowerLab 16/35

240 (ADInstrument, PL3516). Raw data from the EMG sensors were then resampled at a rate of 1 $241 \mathrm{kHz}$ and stored in digital format using Labchart 8 software (ADInstrument, MLU60/8). As shown

242 in Figure 1, bipolar surface EMG recordings were obtained from two speech-related labial 243 muscles: orbicularis oris superior (OOS) and orbicularis oris inferior (OOI), as well as from one 244 non speech-related but negative-affect-related facial muscle: frontalis (FRO) and from one non245 facial and non speech-related muscle: flexor carpi radialis (FCR) on the non-dominant forearm. 246 The latter pair of electrodes was used to check whether the rumination induction would cause any 247 muscle contraction, outside of the facial muscles. The same sensor layout was used for all 248 participants. Asymmetrical movements of the face have been shown in speech and emotional 
249 expression. As reviewed in Everdell, Marsh, Yurick, Munhall, \& Paré (2007), the dominant side

250 of the face displays larger movements than the left during speech production, whereas the non-

251 dominant side is more emotionally expressive. To optimise the capture of speech-related activity,

252 the OOS and OOI sensors were therefore positioned on the dominant side of the body (i.e. the

253 right side for right-handed participants). To optimise the capture of emotion-related activity, the

254 FRO sensor was positioned on the non-dominant side. To minimise the presence of involuntary

255 manual gestures during the recording, the FCR sensor was positioned on the non-dominant side.

256 Each pair of electrodes was placed parallel with the direction of the muscle fibers, at a position

257 distant from the innervation zones and the muscle tendon interface, following the 258 recommendations of DeLuca (1997). The experiment was video-monitored using a Sony HDR-

259 CX240E video camera to track any visible facial movements. A microphone was placed 20 to 30

$260 \mathrm{~cm}$ away from the participant's lips to record any faint vocal production during rumination.

261 Stimuli were displayed with E-prime 2.0 (http://www.pstnet.com) on a 19-inch color monitor.

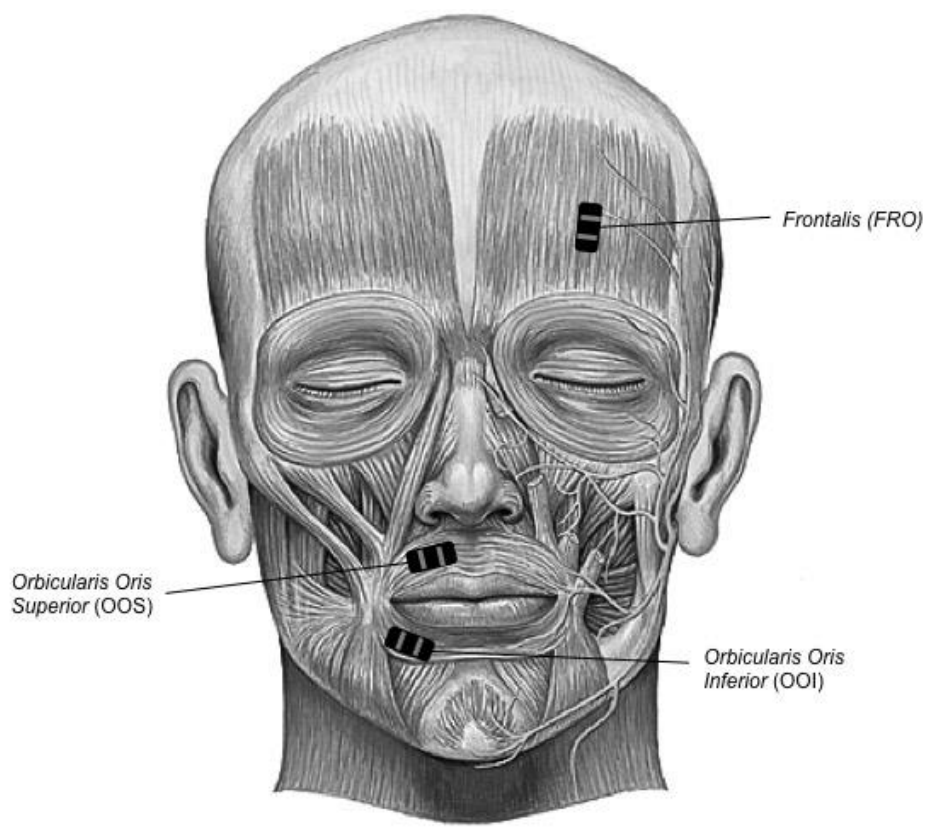




\subsection{Procedure}

This study consisted of two parts. The first part was carried out a week before the EMG

experiment and consisted in checking the inclusion criteria. We checked that participants did not exceed a threshold on a depressive symptoms scale. This was assessed using the French version of the Center for Epidemiologic Studies Depression scale (CES-D; Fuhrer \& Rouillon, 1989), which evaluates the level of depressive symptom in subclinical population. We also collected

272 information about any potential speech, neurologic, neuromuscular or cardiac disorders and about 273 academic curriculum. Finally, the tendency to ruminate (i.e., trait rumination) in daily life was 274 evaluated using the French version of the Mini-CERTS (Cambridge-Exeter Repetitive Thought 275 Scale; Douilliez, Philippot, Heeren, Watkins, \& Barnard, 2014). The second part included two 276 EMG interdependent experiments related to Rumination Induction and Rumination Reduction by

277 Muscle Relaxation. Specifically, Experiment 1 consisted of acquiring physiological EMG data 278 during rest and induced rumination and Experiment 2 consisted of acquiring physiological EMG 279 data after different kinds of relaxation (see below).

280 During both Experiment 1 and Experiment 2, momentary rumination was assessed using 281 four different Visual Analogue Scales (VAS, the first two being adapted and translated to French 282 from Huffziger, Ebner-Priemer, Koudela, Reinhard, \& Kuehner, 2012) rated from 0 to 100: i) “At 283 this moment, I am thinking about my feelings" (referred to as VAS "Feelings"), ii) "At this 284 moment, I am thinking about my problems" (referred to as VAS "Problems"), iii) “At this 285 moment, I am brooding about negative things" (referred to as VAS "Brooding") and iv) "At this 286 moment, I am focused on myself" (referred to as VAS “Focused"). 
Participants were seated in front of a computer screen in a comfortable and quiet room.

290 EMG sensors were positioned as explained above (see Figure 1). Before the rumination

291 induction, each participant underwent a non-specific relaxation session (i.e., without targeting

292 specific muscles) in order to minimize inter-individual initial thymic variability (approximate

293 duration 330 seconds). Immediately after, participants were instructed to remain silent and not

294 to move for one minute to carry out EMG "baseline" measurements. Then, participants' initial

295 level of rumination was assessed using the four VASs.

296 Subsequently, participants were invited to perform a 15-minute I.Q. test, which was

297 presented on the computer screen facing them. They were instructed to correctly respond to three

298 types of I.Q. questions (logical, mathematical and spatial-reasoning questions) in a very short

299 time (30 seconds). Most of the questions were very difficult, if not impossible, to correctly

300 answer in 30 seconds. We included ten different questions for each of the three types of IQ

301 question: ten logical questions (e.g., finding the next number of a Fibonacci sequence), ten

302 mathematical questions (e.g., "What is the result of the following calculus: $(30$ / 165) - (70 / 66)")

303 and ten spatial-reasoning questions (e.g., finding the next figure of a series). Forced-failure tasks

304 have extensively been employed in the literature to induce a slightly negative mood, ideal for

305 subsequent rumination induction (e.g., LeMoult \& Joormann, 2014; Van Randenborgh,

306 Hüffmeier, LeMoult, \& Joormann, 2010).

307 After the I.Q. test, participants were invited to reflect upon the causes and consequences

308 of their feelings, during five minutes (rumination induction). This method is based on the

309 induction paradigm developed by Nolen-Hoeksema and Morrow (1993). The classical paradigm

310 uses a series of prompts. In order to avoid the potential confound in muscle activity induced by

311 silent reading, we did not use the full paradigm. We simply summarised the series of prompts by

312 one typical induction sentence. During this period, participants were asked to remain silent and

313 not to move, while EMG recordings were carried out (i.e., EMG Post-induction measures). EMG 
314 signals of rumination were collected during the last minute of this period. Finally, participants

315 were instructed to self-report momentary rumination on the four VASs.

\subsubsection{Experiment 2: Rumination Reduction by Relaxation}

After Experiment 1, participants were randomly allocated to one of three groups. In the

319 first group, participants listened to a pre-recorded relaxation session that was focused on orofacial 320 speech-related muscles ("Orofacial Relaxation" condition). In the second group, relaxation was 321 focused on the arm muscles (“Arm Relaxation” condition). In the third group, participants simply 322 listened to a story, read by the same person, for an equivalent duration ("Story" condition, 323 detailed content of the story can be found in the Supplementary Materials, in French). In 324 summary, the first condition allowed us to evaluate the effects of targeted speech muscle 325 relaxation on rumination. The second condition allowed evaluating the effects of a non-orofacial 326 relaxation (i.e., speech-unrelated muscles) while the third condition allowed controlling for 327 effects of attentional distraction during relaxation listening.

328 The speeches associated with the three conditions, relaxation sessions and story listening 329 session, were delivered to the participants through loudspeakers. They were recorded by a 330 professional sophrology therapist in an anechoic room at GIPSA-lab (Grenoble, France) and were 331 approximately of the same duration (around 330 seconds).

332 After the relaxation/distraction session, participants were asked to remain silent and not to 333 move during one minute, during which EMG measurements were collected (EMG Post334 relaxation measures). Finally, participants were instructed to self-report rumination on the four 335 VASs. 
EMG signal pre-processing was carried out using Labchart 8. The EMG data were high-

340 pass filtered using a Finite Impulse Response (FIR) filter at a cut-off of $20 \mathrm{~Hz}$, using the Kaiser

341 window method with $\beta=6$. Then, output of this first filter was to a low-pass filtered at a cut-off

342 of $450 \mathrm{~Hz}$ (with the same parameters), in order to focus on the $20-450 \mathrm{~Hz}$ frequency band,

343 following current recommendations for facial EMG studies (DeLuca, 1997; DeLuca, Gilmore,

344 Kuznetsov, \& Roy, 2010; Van Boxtel, 2001).

345 Although we specifically asked participants to remain silent and not to move during EMG

346 data collection, tiny facial movements (such as biting one's lips) or vocal productions sometimes

347 occurred. Periods with such facial movement or vocal production were excluded from the

348 analysis. To do this, visual inspection of audio, video, and EMG signal was performed.

349 Specifically, for the EMG signals, we compared two methods of signal selection. The first one

350 consisted of setting a threshold on the absolute value of the EMG signal and portions of signals

351 above this threshold were removed. This threshold was empirically chosen using visual

352 inspection of a few samples and set to the mean EMG value plus 6 SDs. The second method

353 consisted of manually removing periods of time that included visually obvious bursts of EMG

354 activity, corresponding to overt contraction (as in Rapin et al., 2013). Based on samples from a

355 few participants, the comparisons between these two methods showed that the automatic

356 threshold method was somewhat less sensitive to overt movements. Therefore, the second

357 method was used, as it was more conservative and less prone to leave data related to irrelevant

358 overt movements.

359 After pre-processing, EMG data were exported from Labchart software to Matlab r2014a

360 (Version 8.3.0.532, www.mathworks.fr). For each EMG signal, mean values were computed

361 under Matlab, using 200 ms sliding windows. The average of these mean values were calculated

362 for each recording session (baseline, after induction and after relaxation/induction). This provided 
a score for each muscle of interest (OOS, OOI, FCR, FRO) in each Session (Baseline, Post-

364 Induction, Post-Relaxation) for each participant. ${ }^{2}$

\subsubsection{Statistical analyses}

Absolute EMG values are not meaningful as muscle activation is never null, even in

resting conditions, due in part to physiological noise (Tassinary, Cacioppo, \& Vanman, 2007). In

addition, there are inter-individual variations in the amount of EMG activity in the baseline. To

normalise for baseline activity across participants, we used a differential measure and expressed

371 EMG amplitude as a percentage of baseline level (Experiment 1) or of post-induction level

372 (Experiment 2).

To model EMG amplitude variations in response to the rumination induction (Experiment

374 1) and relaxation (Experiment 2), we used a bayesian multivariate regression model with the 375 natural logarithm of the EMG amplitude (expressed in \% of baseline level) as an outcome, in an 376 intercept-only model (in Experiment 1), and using Condition (Orofacial, Arm or Story) as a 377 categorical predictor in Experiment 2. We used the same strategy (two multivariate models) to analyse VAS scores (expressed in relative changes) along the two experiments.

the probabilistic programming language, Stan (Carpenter et al., 2016). Stan implements gradientbased Markov Chain Monte Carlo (MCMC) algorithms (e.g., Hamiltonian Monte-Carlo), which allow yielding posterior distributions that are straightforward to use for interval estimation around all parameters. Two MCMC simulations (or "chains") were run for each model, including

2 Because of constraints attributable to the design of our experiment, we were not able to perform conventional control measures (e.g., time of the day, food consumption, sport activity, smoking habits, etc.). Moreover, in our study, periods of signal recording had to be shorter than usual HRV analysis time periods (cf. methodology section). Although recent studies suggest that "ultrashort term" HRV analysis seems to correlate quite well with HRV analysis performed on longer periods of time (Brisinda et al., 2013; Salahuddin, Cho, Gi Jeong, \& Kim, 2007), we cannot exclude that our measurements might be unreliable. For these reasons, we chose not to present HRV results in this report and to focus on EMG results as well as subjective reports of rumination. 
385100,000 iterations, a warmup of 10,000 iterations, and a thinning interval of 10 . Posterior 386 convergence was assessed examining autocorrelation and trace plots, as well as the Gelman387 Rubin statistic. Fixed effects were estimated via the posterior mean and $95 \%$ highest density 388 intervals (HDIs), where an HDI interval is the Bayesian analogue of a classical confidence 389 interval. $^{3}$

390 This strategy allowed us to examine posterior probability distribution on each parameter 391 of interest (i.e., effects of session and condition on each response variable). When applicable, we 392 also report evidence ratios (ERs), computed using the hypothesis function of the brms package 393 (Bürkner, in press). These evidence ratios are simply the posterior probability under a hypothesis against its alternative (Bürkner, in press). We also report summary statistics (mean and HDI) of 395 Cohen's d effect sizes, computed from the posterior samples.

\section{Results}

\subsection{Experiment 1: Rumination Induction}

The evolution of VAS scores (for the four assessed scales: Feelings, Problems, Brooding, and Focused) and EMG (for the four muscles: OOS, OOI, FCR and FRO) activity from baseline to post-induction were examined.

\subsubsection{Self-reported rumination measures: VAS scores}

Results for VAS relative changes based on the multivariate models described earlier are

\footnotetext{
${ }^{3}$ While not suffering from the misunderstandings associated with frequentist confidence intervals (for more details, see for instance Morey, Hoekstra, Rouder, Lee \& Wagenmakers, 2016).
} 
407 distribution of the intercept. Raw pre- and post-induction scores are provided in Supplementary 408 Materials.

Mean VAS score on the Feelings scale was slightly lower after induction $(\alpha=-5.55,95 \%$

410 HDI [-10.89, -0.24], $d=-0.23,95 \%$ HDI [-0.46, -0.01]), while Problems score was slightly

411 higher $(\alpha=3.99,95 \%$ HDI $[-2.04,9.83], d=0.15,95 \%$ HDI $[-0.08,0.37])$. We observed a strong

412 increase of the score on the Brooding scale $(\alpha=14.45,95 \%$ HDI $[8.07,20.72], d=0.50,95 \%$

413 HDI [0.26, 0.74]), and a strong decrease on the Focused scale $(\alpha=-11.63,95 \%$ HDI [-17, -6.07$]$,

$414 d=-0.48,95 \%$ HDI $[-0.72,-0.24])$. As we examined the fit of the intercept-only model, these

415 estimates represent the posterior mean for each muscle.

416 In the following, we report the mean (indicated by the Greek symbol $\rho$ ) and the 95\% HDI

417 of the posterior distribution on the correlation coefficient $(\rho)$. Examination of the correlation

418 matrix estimated by the multivariate model revealed no apparent correlation neither between

419 Feelings and Problems scales $(\rho=-.01$, 95\% HDI $[-.23, .22])$, nor between Feelings and 420 Brooding $(\rho=.08,95 \%$ HDI $[-.15, .30])$. However, we observed a strong positive correlation 421 between Problems and Brooding VASs $(\rho=.64$, 95\% HDI $[.49, .76])$, a positive correlation 422 between Feelings and Focused ( $\rho=.30,95 \%$ HDI $[.08, .50])$, and a negative correlation between 423 Problems and Focused ( $\rho=-.30$, 95\% HDI $[-.49,-.08])$, as well as between Brooding and 424 Focused $(\rho=-.18,95 \%$ HDI $[-.39, .05])$.

\subsection{2. $E M G$}

Results for EMG data based on the multivariate model described earlier are shown in the

429 left panel of Figure 2. Summary statistics were computed on posterior samples transformed back 430 from log scale. 
Mean EMG amplitude for OOS was higher after induction $(\alpha=138.57,95 \%$ HDI

$432[124.43,151.71], d=0.66,95 \%$ HDI $[0.49,0.84])$ as well as for OOI $(\alpha=163.89,95 \%$ HDI

433 [145.24, 184.14], $d=0.77,95 \%$ HDI [0.61, 0.94]), and FRO $(\alpha=197.55,95 \%$ HDI [166.59,

$434228.42], d=0.74,95 \%$ HDI $[0.59,0.89])$. Effects on the FCR were approximately null $(\alpha=$

$435100.10,95 \%$ HDI $[97.48,102.76], d=0.01,95 \%$ HDI $[-0.24,0.23])$.

436 Examination of the correlation matrix estimated by the bayesian multivariate model

437 revealed a positive correlation between OOS and OOI EMG amplitudes ( $\rho=.44,95 \%$ HDI [.24,

$438.61])$, while no apparent correlations neither between OOS and FCR $(\rho=.09,95 \%$ HDI [-.14,

$439.31])$, OOS and FRO $(\rho=.12,95 \%$ HDI $[-.11, .35])$, OOI and FCR $(\rho=.02,95 \%$ HDI $[-.21$,

$440.25])$, FRO and FCR $(\rho=-.06,95 \%$ HDI $[-.28, .17])$, nor OOI and FRO $(\rho=.07,95 \%$ HDI $[-.16$,

$441.29]$ ). Scatterplots, marginal posterior distributions and posterior distributions on correlation

442 coefficients are available in Supplementary Materials.

In order to check whether the propensity to ruminate could predict the effects of the 445 rumination induction on EMG amplitude, we compared the multivariate model described above, 446 with a similar model but with the score on the abstract dimension of the Mini-CERTS as an 447 additional predictor. We compared these models using the widely applicable information 448 criterion (WAIC; Watanabe, 2010), via the WAIC function of the brms package (Bürkner, in 449 press). Results showed that the intercept-only model had a lower WAIC (WAIC $=177.39)$ than 450 the more complex model (WAIC $=182.01$ ), indicating that there is no predictive benefit in 451 adding the Mini-CERTS score as a predictor. 

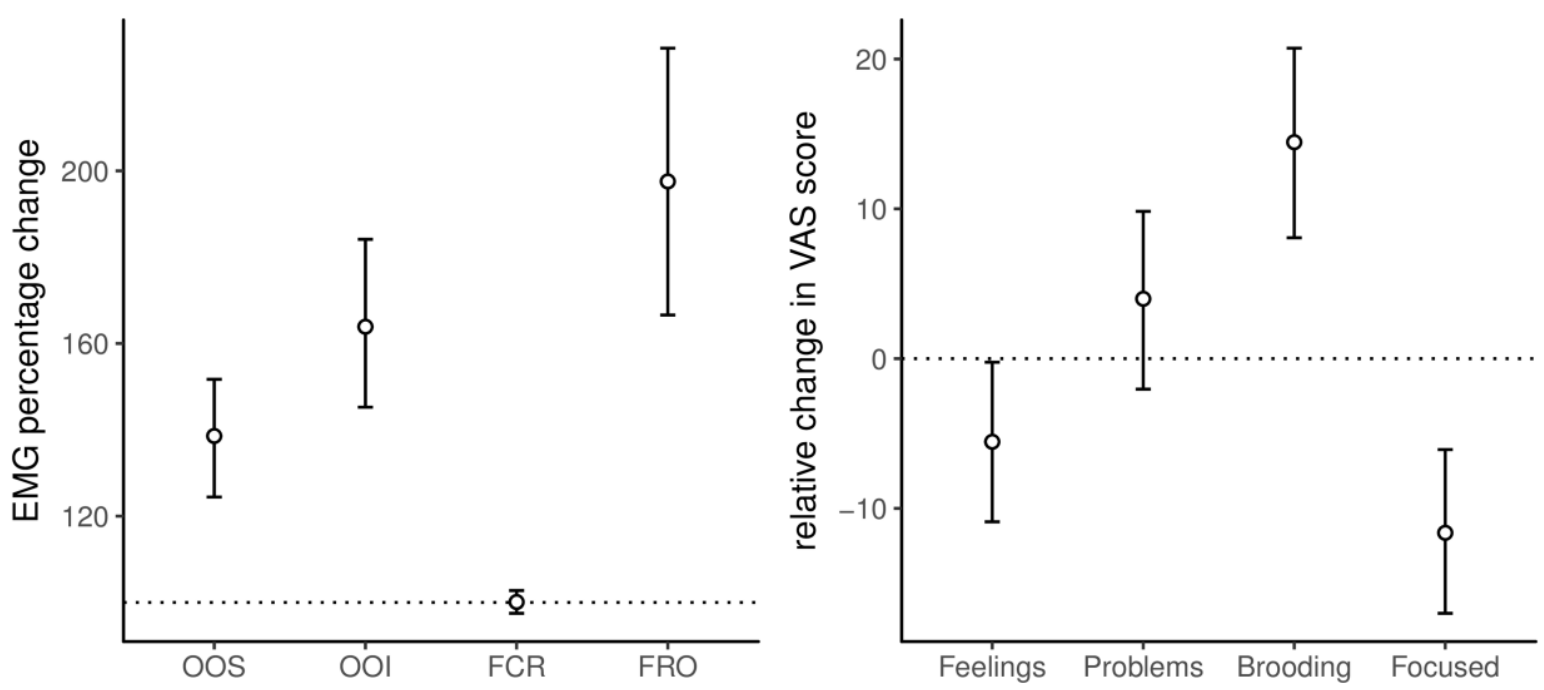

\subsubsection{Correlations between EMG amplitudes and VAS scores}

458 BayesianFirstAid package (Bååth, 2013), using 15,000 iterations for each correlation coefficient.

459 Both estimated correlation coefficients ( $\rho)$ and 95\% HDIs are reported in Table 1.

460

\begin{tabular}{ccccc}
\hline VAS / Muscle & OOS & OOI & FCR & FRO \\
\hline Feelings & -0.07 & 0.01 & -0.20 & -0.05 \\
& {$[-0.32,0.18]$} & {$[-0.24,0.25]$} & {$[-0.43,0.04]$} & {$[-0.29,0.19]$} \\
Problems & 0.11 & -0.01 & -0.09 & $\mathbf{0 . 2 6}$ \\
& {$[-0.14,0.34]$} & {$[-0.25,0.23]$} & {$[-0.33,0.15]$} & {$[\mathbf{0 . 0 2}, \mathbf{0 . 5 0}]$} \\
Brooding & -0.03 & 0.11 & $\mathbf{- 0 . 2 6}$ & 0.11 \\
& {$[-0.27,0.20]$} & {$[-0.12,0.34]$} & {$[-\mathbf{0 . 4 7}, \mathbf{- 0 . 0 3}]$} & {$[-0.13,0.36]$} \\
Focused & -0.18 & $\mathbf{- 0 . 2 6}$ & -0.07 & 0.01 \\
& {$[-0.41,0.06]$} & {$[-\mathbf{0 . 4 7}, \mathbf{- 0 . 0 3}]$} & {$[-0.31,0.18]$} & {$[-0.24,0.26]$}
\end{tabular}

Table 1. (Single column)

462 
In the second experiment, we aimed at comparing the evolution in EMG activity and VAS

465

466

467

468

469

470

471

\begin{tabular}{|c|c|c|c|}
\hline VAS & Condition & $\beta[95 \% \mathrm{HDI}]$ & $d[95 \% \mathrm{HDI}]$ \\
\hline \multirow[t]{3}{*}{ Feelings } & Orofacial & $7.84[-0.34,16.05]$ & $0.38[-0.02,0.80]$ \\
\hline & Arm & $4.60[-3.78,13]$ & $0.22[-0.21,0.62]$ \\
\hline & Story & $-5.33[-13.41,2.89]$ & $-0.26[-0.68,0.12]$ \\
\hline \multirow[t]{3}{*}{ Problems } & Orofacial & $-15.24[-23.89,-6.50]$ & $-0.70[-1.11,-0.28]$ \\
\hline & Arm & $-4.23[-13.15,4.69]$ & $-0.19[-0.59,0.22]$ \\
\hline & Story & $-9.19[-17.90,-0.39]$ & $-0.42[-0.83,-0.02]$ \\
\hline \multirow[t]{3}{*}{ Brooding } & Orofacial & $-20.40[-28.78,-11.97]$ & $-0.97[-1.41,-0.55]$ \\
\hline & Arm & $-10.42[-18.87,-1.93]$ & $-0.50[-0.90,-0.07]$ \\
\hline & Story & $-15.16[-23.48,-6.83]$ & $-0.72[-1.12,-0.30]$ \\
\hline \multirow[t]{3}{*}{ Focused } & Orofacial & $17.03[7.37,20.67]$ & $0.72[0.29,1.14]$ \\
\hline & Arm & $11.19[1.56,20.89]$ & $0.48[0.05,0.88]$ \\
\hline & Story & $-14.94[-24.64,-5.32]$ & $-0.64[-1.05,-0.22]$ \\
\hline
\end{tabular}

scores from post-induction to post-relaxation in three different conditions: Orofacial relaxation, Arm relaxation, and listening to a Story.

\subsubsection{Self-reported rumination measures: VAS scores}

Posterior means and 95\% HDIs of the VAS scores in each condition of experiment 2 are represented in Figure 3 and Table 1.

Table 2. (Single column)

472

473

474

475

476

477

478

.

In order to compare the effects of the two kind of relaxation on the VAS scores, we then used the hypothesis function of the brms package that allows deriving evidence ratios (ER). These evidence ratios are simply the posterior probability under a hypothesis (e.g., the hypothesis that the Orofacial relaxation session would be more effective in reducing self-reported rumination than the Arm relaxation session) against its alternative (Bürkner, in press). 
480 (as their scores increased after induction in Experiment 1), our analyses were focused on these 481 two scales.

482 Concerning the Problems VAS, the decrease observed in the Orofacial condition was 483 more pronounced than in the Arm condition $\left(\mathrm{Est}=-11.06, \mathrm{SE}=6.35, \mathrm{ER}_{10}=22.65\right)$, and slightly 484 more pronounced compared to the Story condition (Est $\left.=-6.05, \mathrm{SE}=6.31, \mathrm{ER}_{10}=4.98\right)$. The 485 observed on the Brooding VAS score in the Orofacial condition was larger than in the Arm 486 condition $\left(\mathrm{Est}=-9.98, \mathrm{SE}=6.07, \mathrm{ER}_{10}=18.85\right)$, and slightly more important compared to the 487 Story condition $\left(\mathrm{Est}=-5.23, \mathrm{SE}=6.01, \mathrm{ER}_{10}=4.27\right)$.

488

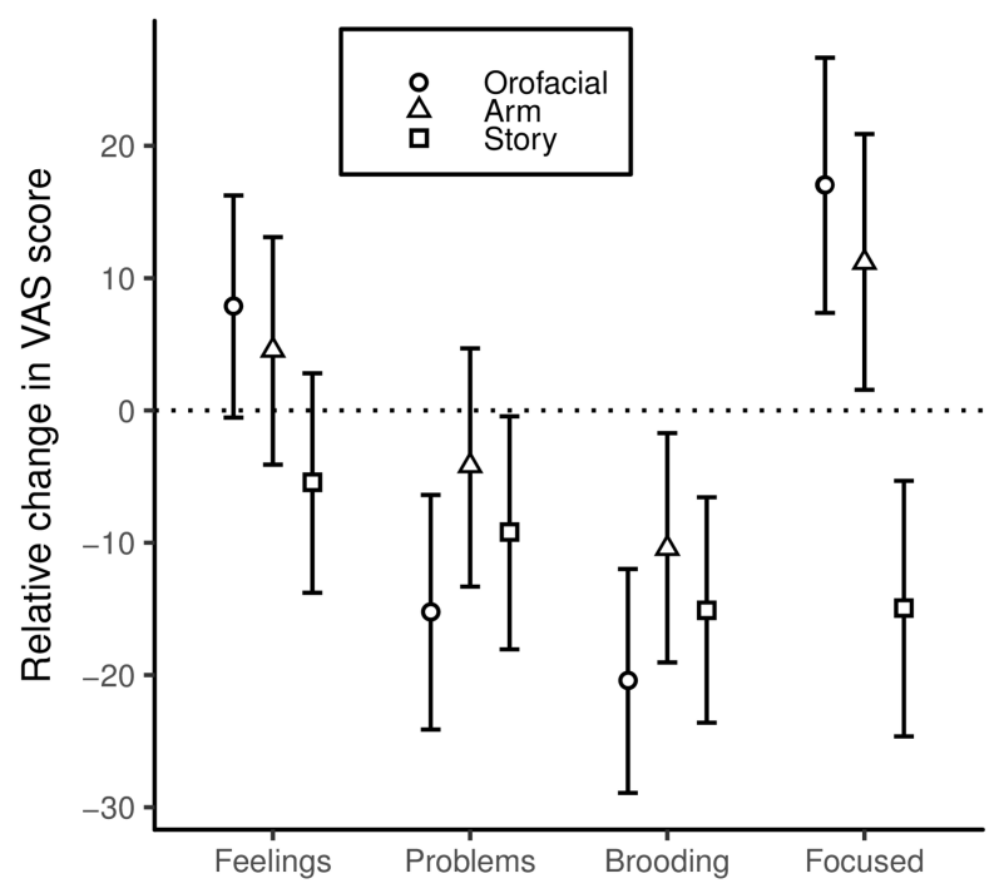


495 are represented in Figure 4 and reported in Table 3.

496

\begin{tabular}{|c|c|c|c|}
\hline Muscle & Condition & $\beta[95 \% \mathrm{HDI}]$ & $d[95 \% \mathrm{HDI}]$ \\
\hline \multirow[t]{3}{*}{ OOS } & Orofacial & $69.80[56.96,83.62]$ & $-0.92[-1.54,-0.32]$ \\
\hline & Arm & $98[79.83,117.71]$ & $-0.07[-0.48,0.32]$ \\
\hline & Story & $109.54[89.05,130.74]$ & $0.16[-0.21,0.49]$ \\
\hline \multirow[t]{3}{*}{ OOI } & Orofacial & $71.05[52.67,90.71]$ & $-0.62[-1.24,-0.08]$ \\
\hline & Arm & $100.43[74.05,128.68]$ & $-0.03[-0.42,0.34]$ \\
\hline & Story & $89.94[66.54,114]$ & $-0.19[-0.63,0.22]$ \\
\hline \multirow[t]{3}{*}{ FCR } & Orofacial & $97.01[93.12,100.89]$ & $-0.32[-0.75,0.10]$ \\
\hline & Arm & $98.46[94.51,102.48]$ & $-0.16[-0.58,0.25]$ \\
\hline & Story & $99.24[95.26,103.18]$ & $-0.08[-0.48,0.32]$ \\
\hline \multirow[t]{3}{*}{ FRO } & Orofacial & $59.22[48.18,70.93]$ & $-1.44[-2.20,-0.70]$ \\
\hline & Arm & $61.31[49.69,73.82]$ & $-1.32[-2.08,-0.61]$ \\
\hline & Story & $98.31[80.19,117.29]$ & $-0.06[-0.46,0.32]$ \\
\hline
\end{tabular}

499 We used the same strategy as before to compare the effects of the two kinds of relaxation 500 on the EMG amplitudes.

501 Concerning the OOS, the observed decrease in the Orofacial condition was more 502 pronounced than in the Arm condition $\left(\mathrm{Est}=-0.34, \mathrm{SE}=0.14, \mathrm{ER}_{10}=140.73\right)$, as well as 503 concerning the OOI $\left(\right.$ Est $\left.=-0.35, \mathrm{SE}=0.19, \mathrm{ER}_{10}=29.46\right)$, while we observed no noticeable 504 differences between the two kinds of relaxation concerning the EMG amplitude of the FRO (Est $\left.505=-0.04, \mathrm{SE}=0.14, \mathrm{ER}_{10}=1.53\right)$. 


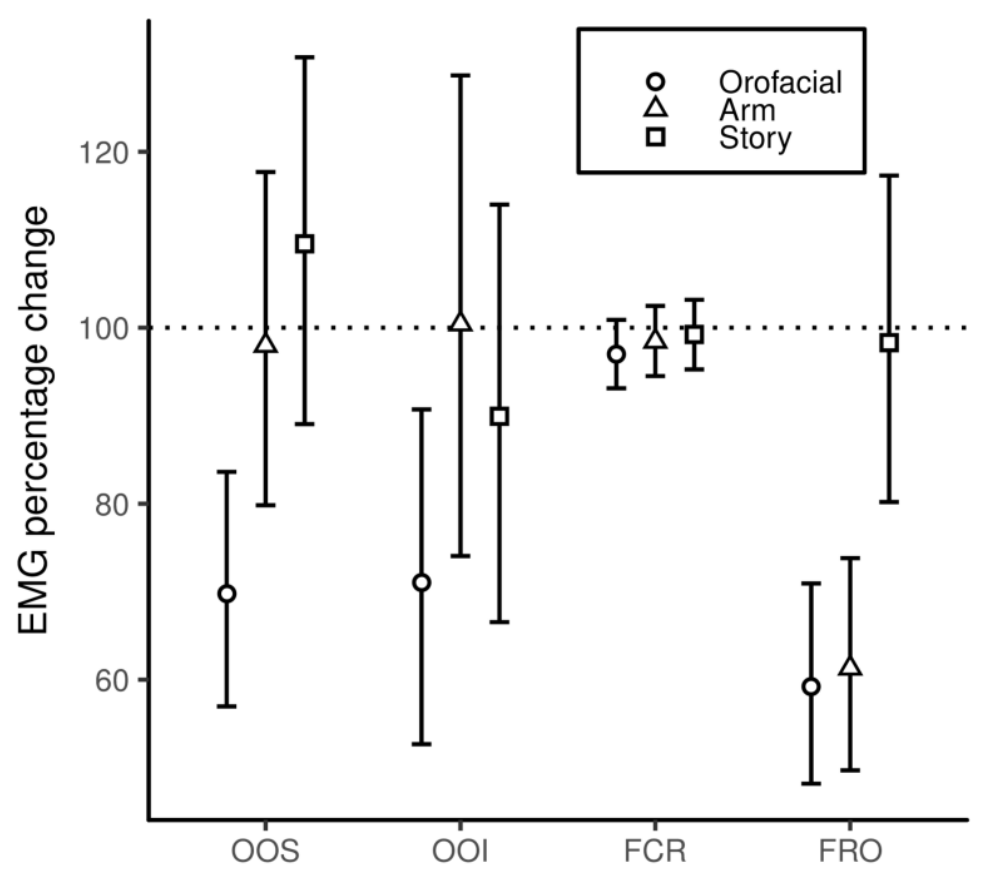

Figure 4. (Single column)

\section{Discussion}

\subsection{Experiment 1}

511 In the first experiment, we examined electromyographic correlates of induced rumination

512 in healthy individuals. According to the Motor Simulation view, we predicted an increase in the

513 activity of all facial muscles after the rumination induction, associated with an increase in self-

514 reported rumination. Alternatively, the Abstraction view predicted an increase in self-reported

515 rumination associated with an increase in forehead activity with no changes in either lip or

516 forearm activity.

517 To test the predictions of these two theoretical views, we compared EMG measures and

518 VAS scores after induction to their values before induction. EMG activity was examined in four

519 muscles: OOS and OOI, two muscles involved in speech production, FRO, a facial negative-

520 affect-related but not speech-related muscle, and FCR, a non-facial control muscle on the non-

521 dominant forearm. 
As predicted by the Motor Simulation view, we observed an increase in the activity of the

523 two speech-related muscles (OOS \& OOI) as well as in the negative-affect-related muscle (FRO)

524 and no change in FCR activity. The increase in facial EMG together with the increase in the

525 subjective reports of rumination suggests that facial EMG increase is a correlate of verbal

526 rumination. As supported by several studies results, the forehead muscle activity has been

527 associated with unpleasant emotions (Jäncke et al., 1996) or anxiety (Conrad \& Roth, 2007). The

528 increase in FRO activity observed here is consistent with the increase in negative emotions

529 induced by our negatively valenced induction procedure. Orbicularis oris lip muscles are

530 associated with speech production. The increase in lip activity observed here suggests that the

531 speech motor system was involved during the ruminative phase. The fact that the FCR remained

532 stable after rumination induction suggests that the observed facial activity increase was not due to

533 general body tension induced by a negative mental state. These facial EMG results therefore

534 support the hypothesis that rumination is an instance of articulatory-specified inner speech.

535 After the rumination induction, a larger increase in OOI activity was observed compared

536 to the increase in OOS activity. This finding is consistent with previous findings of higher EMG

537 amplitude in the lower lip during speech and inner speech (e.g., Barlow \& Netsell, 1986; Regalo

538 et al., 2005; Sokolov, 1972) or auditory verbal hallucinations (Rapin et al., 2013). Rapin et al.

539 (2013) have explained the difference between the activities of the two lip muscles by muscle

540 anatomy. The proximity of the OOI muscle with other speech muscles (such as the depressor

541 angular muscle or the mentalis) could increase the surface EMG signal captured on the lower lip

542 (OOI), as compared to the upper lip (OOS) during speech. An even larger increase in FRO

543 activity was observed compared to the increase in lip muscle activity. As EMG amplitude is

544 known to vary with muscle length (Babault, Pousson, Michaut, \& Van Hoecke, 2003), the greater

545 increase in frontalis activity could be explained by its anatomical properties. 
However, although a functional distinction can be drawn between the forehead and the lip

547 muscles, one should acknowledge the fact that these two sets of muscles can be commonly

548 activated during some behaviours. For instance, Van Boxtel \& Jessurun (1993) have shown that

549 orbicularis oris inferior and frontalis were both activated during a two-choice serial reaction task

550 in which nonverbal auditory or visual signals were presented. Moreover, there was a gradual

551 increase in EMG activity in these muscles during the task, either when the task was prolonged or

552 when the task was made more difficult. They interpreted this increase in EMG activity as

553 associated with a growing compensatory effort to keep performance at an adequate level. An

554 alternative interpretation is that the increase in task difficulty was dealt with by inner

555 verbalization. Covertly rehearsing the instructions or covertly qualifying the stimuli might have

556 helped the participants to perform adequately. Therefore, the increase in orbicularis oris activity

557 might have been related to an increase in covert verbalization, whereas the increase in frontalis

558 activity might have been related to increased anxiety or tension. The fact that the EMG increase

559 was muscle specific, and that some facial muscles (orbicularis oculi, zygomaticus major,

560 temporalis) did not show an increase in activity unless the task became too difficult, supports this

561 interpretation. It cannot be ruled out, however, that orbicularis oris activity may in some cases be

562 related to mental effort without mental verbalisation. Nevertheless, although the IQ test itself was

563 designed to induce mental effort, no cognitively demanding task was asked to the participant

564 during the period of EMG recording (i.e., approximately four minutes after the end of the test).

565 Although we cannot absolutely exclude that rumination in itself could require cognitive effort, it

566 seems unlikely that mental effort was the main factor of variation.

567 Scores on the VAS need to be discussed in further detail. We examined which VAS scales

568 were most suitable to capture changes in state rumination to allow focused analyses. Due to the

569 "pre-baseline" relaxation session, during which participants were asked to concentrate on their

570 body and breathing cycles, participants reported a high level of attentional self-focus at baseline 
571 ("Feelings" and "Focused" VAS). Because of the high level of self-focused attention at baseline,

572 it is likely that the scores on the "Feelings" and "Focused" VAS did not show the expected

573 increase after rumination induction (ceiling effect). The scores on the scales "Problems" and

574 "Brooding", which are more representative of maladaptive rumination, did increase after our

575 rumination induction paradigm, however. Interestingly, the "Brooding" VAS corresponded to a

576 larger increase and seemed to be more sensitive to rumination induction than the "Problems"

577 VAS. Given this greater sensibility and the strong positive correlation between the "Brooding"

578 and the "Problems" VAS, it thus make sense to consider the "Brooding" VAS as a better estimate

579 of ruminative state, at least within our paradigm. We will therefore only use this scale to assess

580 rumination in the following.

581 The fact that we did not observe any association between the propensity to ruminate (as

582 measured by the Mini-CERTS questionnaire) and the effects of the induction is consistent with

583 the results of Rood, Roelofs, Bögels, and Arntz (2012) who found that the level of trait

584 rumination did not moderate the effects of a rumination induction.

\subsection{Experiment 2}

In the second experiment, we studied the effects of two muscle-specific relaxation 588 sessions: Orofacial relaxation and Arm relaxation. We compared their effects to a third control 589 condition (Story), which did not involve the deliberate relaxation of any specific muscle. Our 590 predictions were that a decrease in facial EMG activity should be observed in each condition. If 591 the Motor Simulation view is correct, we expected a larger decrease in the activity of all facial 592 muscles in the "Orofacial relaxation" condition than in the "Arm relaxation" condition, 593 associated with a larger decrease in self-reported rumination. Additionally, we expected a more 594 pronounced decrease in the two relaxation conditions (orofacial and arm relaxation conditions) 
595 than in the control ("Story") condition. We also expected no difference between relaxation 596 conditions regarding the change in the forearm muscle activity.

597 The data indicated a decrease in self-reported rumination ("Brooding" VAS) in each 598 condition. The "Orofacial" relaxation condition elicited a slightly larger decrease than the "Arm 599 relaxation" or the "Story" condition. However, there was extensive individual variation in 600 response to these conditions. As concerns EMG results, we observed a decrease in OOS and OOI 601 activities in all three conditions but this decrease was more pronounced in the orofacial condition 602 than in the other two conditions. The frontalis activity did not show the same pattern. A similar 603 FRO activity decrease was observed in both the orofacial and the non-orofacial relaxation 604 conditions. Therefore, in Experiment 2, the lip muscles and the forehead muscle follow 605 differential evolutions. A dissociation was observed: whereas both orofacial and arm relaxations resulted in a decrease in forehead activity, only orofacial relaxation was successful at reducing lip 607 activity.

Considering both VAS results and the dissociation in EMG patterns, several 609 interpretations are possible. The first interpretation is that verbal production associated with 610 rumination was more reduced by orofacial muscular relaxation than by non-orofacial relaxation.

611 This interpretation is consistent with the fact that the "Brooding" VAS was slightly more 612 decreased in this condition compared to the other two. The larger decrease in OOS and OOI 613 amplitude after orofacial relaxation would thus reflect this reduction in verbal production, as 614 hypothesised by the Motor Simulation view. The fact that FRO activity displayed a similar 615 decrease in both orofacial and non-orofacial relaxation conditions could suggest that any means 616 of body relaxation (be it orofacial or not) is appropriate to reduce negative affect and can 617 therefore reduce forehead contraction. This suggests that the FRO activity increase presumably 618 reflected negative affect and tension (such as observed in EMG studies on generalised anxiety 619 disorder patients, see Conrad \& Roth, 2007 for a review). 
Alternatively, one could also argue that the larger decrease in lip muscle activity after

621 orofacial relaxation finds a more trivial explanation in that it seems obvious to expect that

622 orofacial relaxation will be more efficient to reduce lip muscle contraction than non-orofacial

623 relaxation. Thus, the different impacts of the two relaxation sessions on the lip muscles would not

624 be related to reduced rumination per se but simply to a more anatomically targeted relaxation.

625 However, several observations argue against such an interpretation. The larger decrease in the

626 "Brooding" VAS in the orofacial relaxation condition compared with the other conditions

627 suggests that the reduction in lip muscle activity is indeed related to the reduction in rumination.

628 Moreover, an interpretation solely based on anatomical links does not explain why FRO activity

629 displayed the same amount of reduction in both relaxation sessions. If reduction in muscle

630 activity was merely related to the effect of facial muscle relaxation, then the decrease in FRO

631 activity should have also been higher in the orofacial relaxation condition than in the other

632 relaxation condition, which was not the case. Therefore the dissociation between forehead and lip

633 patterns of activity, together with the differential effects of the two types of relaxation on

634 subjective rumination reports strongly suggest that different processes underlie the activity of

635 these two sets of muscles. We therefore consider that the first interpretation is more plausible:

636 frontalis activity seems related to overall facial tension due to negative affect whereas lip activity

637 seems to be related to the specific involvement of the speech musculature in rumination. These

638 results thus seem to confirm the interpretation of decreased OOS and OOI activities in the

639 orofacial relaxation condition as markers of rumination reduction.

640 Interestingly, we observed no changes of forearm EMG activity in any of the three

641 conditions of experiment 2. The fact that the relaxation session focused on the forearm was not

642 associated with a decrease in FCR activity has a simple explanation: FCR activity had not

643 increased after rumination induction and had remained at floor level. The forearm was thus

644 already relaxed and the Arm relaxation session did not modify FCR activity. Another interesting 
645 conclusion related to this absence of modification of forearm activity is that relaxation does not

646 spuriously decrease muscle activity below its resting level. One possible interpretation of the

647 increase in lip EMG after rumination induction could have been that baseline relaxation

648 artificially decreased baseline activity under its resting level. The facts that forearm activity did

649 not decrease after arm-focused relaxation contradicts this interpretation.

650 Finally, the "Story" condition was also associated with a decrease in OOI and FRO

651 activities. This could mean that listening to a story reduced rumination to the same extent as

652 relaxation did. However, the discrepancy observed in "Focused" VAS between the two relaxation

653 conditions on the one hand and the control condition on the other hand, suggests that the EMG

654 decrease observed in the "Story" condition might be attributable to a different cause than that

655 observed in the two relaxation conditions. Listening to a story could help reducing rumination by

656 shifting attention away from ruminative thoughts. Relaxation sessions could help reducing

657 rumination by shifting attention to the body in a beneficial way.

\subsection{General discussion}

660 We set out two experiments to examine whether rumination involves motor simulation or

661 is better described as linguistically abstract and articulatory impoverished. We used labial, facial, 662 and arm EMG measures to assess potential articulatory correlates of rumination. The patterns of 663 results of our study seem to be in favour of the motor nature of verbal rumination. In Experiment 6641 , rumination induction was associated with a higher score on the scale "I am brooding about 665 negative things" which is representative of abstract-analytical rumination, considered as verbal 666 rumination. This maladaptive rumination state was associated with an increase in the activity of 667 two speech-related muscles, without modification of the arm muscle activity, which indicates that 668 rumination involves activity in speech articulatory muscles, specifically. The concurrent increase 669 in forehead muscle activity could be explained by an increase in negative emotions induced by 
670 our negatively valenced induction procedure. The results of Experiment 1 therefore show the

671 involvement of the speech musculature during rumination. This is in line with the Motor

672 simulation view, according to which inner speech is fully specified at the articulatory level, not

673 just the lexical level.

674 In Experiment 2, guided relaxation resulted in a decrease in speech muscle activity. In the

675 lip muscles, the activity decrease was stronger after orofacial relaxation than after arm-focused

676 relaxation. In the forehead muscle, however the effect was the same for both types of relaxation.

677 This decrease in speech muscle activity was associated with a decrease in self-reports of 678 rumination and was most pronounced after orofacial relaxation. These findings suggest that a

679 reduction in speech muscle activity could hinder articulatory simulation and thus limit inner 680 speech production and therefore reduce rumination. This interpretation is consistent with the

681 Motor Simulation view of inner speech. Brooding-type rumination was also diminished after the 682 arm-focused relaxation as well as after listening to a story, although less than in the orofacial 683 relaxation. This suggests that general relaxation or distraction are also likely to reduce negative 684 rumination. To summarize, experiments 1 and 2 are consistent with the Motor Simulation view of 685 inner speech, according to which speech muscle activity is inherent to inner speech production.

686 Experiment 1 shows the involvement of the lip musculature during brooding-type rumination. 687 Experiment 2 suggests that brooding-type rumination could be reduced by blocking or relaxing 688 speech muscles.

689 These data support the utility of labial EMG as a tool to objectively assess inner speech in 690 a variety of normal and pathological forms. We suggest that this method could be used as a 691 complement to self-report measures, in order to overcome limitation of these measures.

692 Our results should be interpreted with some limitations in mind. Firstly, our sample 693 consisted exclusively of women. Although this methodological choice makes sense considering 694 the more frequent occurrence of rumination in women, further studies should be conducted to 
695 ascertain that our results may generalize to men. Secondly, in Experiment 1, no between-subject

696 control condition was used to compare with the group of participants who underwent rumination

697 induction. Thus, we cannot rule out that other processes occurred between baseline and

698 rumination induction, influencing responding. Thirdly, substantial inter-individual differences

699 were observed concerning the size of the effect of rumination induction on facial EMG activity.

700 The results of Jäncke (Jäncke, 1996; Jäncke et al., 1996) can shed light on this last result. Jäncke

701 used a similar procedure (i.e., negative mood induction using a false I.Q. test and facial EMG

702 measurements to assess emotions), except that the experimenter was not in the room while

703 participants performed the test and acknowledged their results. The experimenter then came back

704 to the room and analysed participants' behaviours. Jäncke observed an increase in facial muscular

705 activity (assessed when participants were reading their results) only in participants who were

706 prone to express their distress when the experimenter came back, while more introverted

707 participants did not show any increased facial activity when reading their results. Jäncke

708 interpreted these results in the framework of an ecological theory of facial expression, suggesting

709 that facial expressions would not only be guided by underlying emotions, but also by their

710 communicative properties. Considering these results, it seems likely that the proneness of

711 participants to communicate their emotions could have mediated effects of the induction on their

712 facial EMG activity. This could partially explain the observed inter-individual variability in facial

713 EMG activity associated with rumination. Moreover, even though rumination is a predominantly

714 verbal process, one cannot exclude that some of our participants experienced rumination in

715 another modality (e.g., imagery-based rumination), which would explain their lower than average

716 lip activity.

717 Thus, a logical next step is to examine qualitative factors that mediate the link between

718 rumination and facial muscular activity. These factors (among others) could be proneness to

719 communicate emotion or proneness to verbalize affects. Additionally, recent studies suggest a 
720 link between verbal aptitudes and propensity to ruminate. Uttl, Morin and Hamper (2011) have

721 observed a weak but consistent correlation between the tendency to ruminate and scores on a

722 verbal intelligence test. Penney, Miedema and Mazmanian (2015) have observed that verbal

723 intelligence constitutes a unique predictor of rumination severity in chronic anxious patients. To

724 our knowledge, the link between verbal intelligence and induced rumination has never been

725 studied. It would be interesting to examine whether the effects of a rumination induction could be

726 mediated by verbal intelligence, and to what extent this could influence related facial EMG

727 activity.

728 In conclusion, this study provides new evidence for the facial embodiment of rumination,

729 considered as a particular instance of inner speech. Even if more data are needed to confirm these

730 preliminary conclusions, our results seem to support the Motor Simulation view of inner speech

731 production, manifested as verbal rumination. In addition, facial EMG activity provides a useful

732 means to objectively quantify the presence of verbal rumination. 


\section{Supplementary materials}

735 Supplementary materials, data, reproducible code and figures are available at:

736 https://osf.io/882te/?view_only=c4c24a38bbbb43c0aa5c49ea4478786c. This link is a "view-

737 only" link, heading toward a private project, provided at the reviewing stage. The final link will

738 head toward a public project.

\section{Acknowledgements}

This project was funded by the ANR project INNERSPEECH [grant number ANR-13-

742 BSH2-0003-01]. The first author of the manuscript is funded by a fellowship from Université

743 Grenoble Alpes and a grant from the Pôle Grenoble Cognition. We thank Nathalie Vallet for

744 recording the relaxation and distraction sessions. We thank our colleagues from GIPSA-lab:

745 Marion Dohen for her help in the recording of the audio stimuli in the anechoic room at GIPSA-

746 lab, as well as Christophe Savariaux and Coriandre Vilain for their advice in the audio setup

747 associated with the EMG measures. We are also grateful to Rafael Laboissière and Adeline

748 Leclercq Samson for their advice concerning data analysis. We sincerely thank two anonymous

749 reviewers for their critical reading of our manuscript and their many insightful comments and

750 suggestions. Access to the facility of the MSH-Alpes SCREEN platform for conducting research

751 is gratefully acknowledged. 


\section{References}

754

755

756

757

758

759

760

761

762

763

764

765

766

767

768

769

770

771

772

773

774

775

776

777

778

779

780

781

782

783

784

785

786

787

788

789

790

791

792

793

794

Bååth,

R.

(2013).

"Bayesian First

Aid".

Retrieved

from https://github.com/rasmusab/bayesian_first_aid

Babault, N., Pousson, M., Michaut, A., \& Van Hoecke, J. (2003). Effects of quadriceps femoris muscle length on neural activation during isometric and concentric contractions. Journal of Applied Physiology, 94(3), 983-990. http://doi.org/10.1152/japplphysiol.00717.2002

Baddeley, A., \& Wilson, B. (1985). Phonological coding and short-term memory in patients without speech. Journal of Memory and Language, 24(4), 490-502. http://doi.org/10.1016/0749-596x(85)90041-5

Barlow, S. M., \& Netsell, R. (1986). Differential Fine Force Control of the Upper and Lower Lips. Journal of Speech, Language, and Hearing Research, 29(2), 163-169. http://doi.org/10.1044/jshr.2902.163

Basho, S., Palmer, E. D., Rubio, M. A., Wulfeck, B., \& Müller, R. A. (2007). Effects of generation mode in fMRI adaptations of semantic fluency: paced production and overt speech. Neuropsychologia, 45(8),

1697-1706. http://doi.org/10.1016/j.neuropsychologia.2007.01.007

Boyd, E. M., \& Fales, A. W. (1983). Reflective learning. Key to learning from experience. Journal of Humanistic Psychology, 23(2), 99-117. http://dx.doi.org/ $10.1177 / 0022167883232011$.

Brewer, W. F. (1986). What is autobiographical memory? In: D. Rubin (ed.), Autobiographical Memory, 25-49. Cambridge, UK: Cambridge University Press. http://doi.org/10.1017/cbo9780511558313.006

Brisinda, D., Venuti, A., Sorbo, A. R., Cataldi, C., Iantorno, E., \& Fenici, R. (2013). Comparison between standard short-term, very-short and ultra-short-term heart rate variability analysis in healthy subjects during exercise testing. European Heart Journal, 34, 3384. http://doi.org/10.1093/eurheartj/eht309.p3384

Bürkner, P.-C. (in press). brms: An R Package for Bayesian Multilevel Models using Stan. Journal of Statistical Software.

Carpenter, C., Gelman, A., Hoffman, M., Lee, D., Goodrich, B., Betancourt, M., ... Riddell, A. (2016). Stan: A probabilistic programming language. Journal of Statistical Software, in press.

Cefidekhanie, A. H., Savariaux, C., Sato, M., \& Schwartz, J. L. (2014). Interaction between articulatory gestures and inner speech in a counting task. Journal of the Acoustical Society of America, Acoustical Society of America, 136(4), 1869-1879. http://doi.org/10.1121/1.4893910

Conrad, A., \& Roth, W. T. (2007). Muscle relaxation therapy for anxiety disorders: It works but how ? Journal of Anxiety Disorders, 21, 243-264. http://doi.org/10.1016/j.janxdis.2006.08.001

Conrad, B., \& Schönle, P. (1979). Speech and respiration. Archiv für Psychiatrie und Nervenkrankheiten, 226(4), 251-268. http://doi.org/10.1007/bf00342238

Conway, M. A. (1990). Autobiographical Memory: An Introduction. Milton Keynes, UK: Open University Press. 
Corley, M., Brocklehurst, P. H., \& Moat, H. S. (2011). Error biases in inner and overt speech: Evidence from tongue twisters. Journal of Experimental Psychology: Learning, Memory, and Cognition, 37, 162-175. http:// dx.doi.org/10.1037/a0021321

Decety, J., \& Jeannerod, M. (1996). Mentally simulated movements in virtual reality: does Fitt's law hold in motor imagery? Behavioral Brain Research, 72, 127-134. http://doi.org/10.1016/0166-4328(96)00141-6

Dell, G. S., \& Repka, R. J. (1992). Errors in inner speech. In Experimental Slips and Human Error (pp. 237-262). Springer US. http://doi.org/10.1007/978-1-4899-1164-3_10

DeLuca, C. J. (1997). The Use of Surface Electromyography in Biomechanics. Journal of Applied Biomechanics, 13(2), 135-163. http://doi.org/10.1123/jab.13.2.135

DeLuca, C. J., Gilmore, L. D., Kuznetsov, M., \& Roy, S. H. (2010). Filtering the surface EMG signal: Movement artifact and baseline noise contamination. Journal of Biomechanics, 43(8), 1573-1579. http://doi.org/10.1016/j.jbiomech.2010.01.027

Douilliez, C., Philippot, P., Heeren, A., Watkins, E., \& Barnard, P. (2014). The Mini-CERTS (Cambridge-Exeter Repetitive Thought Scale): A short questionnaire to assess constructive and unconstructive repetitive thinking. Revue Canadienne Des Sciences Du Comportement/ Canadian Journal of Behavioural Science, 46(2), 1985-192.

Ekman, P. (2003). Emotions Revealed. Understanding Faces and Feelings. London: Weidenfeld \& Nicolson.

Ekman, P., Friesen, W. V. (1978). The Facial Action Coding System (FACS): a technique for the measurement of facial action. Palo Alto (CA): Consulting Psychologists Press.

Everdell, I. T., Marsh, H., Yurick, M. D., Munhall, K. G., \& Paré, M. (2007). Gaze behaviour in audiovisual speech perception: asymmetrical distribution of face-directed fixations. Perception, 36, 1535-1545.

Feinberg, I. (1978). Efference copy and corollary discharge: Implications for thinking and its disorders. Schizophrenia Bulletin, 4(4), 636-640. http://doi.org/10.1093/schbul/4.4.636

Fuhrer, R., \& Rouillon, F. (1989). La version française de l'échelle CES-D (Center for Epidemiologic Studies-Depression Scale). Description et traduction de l'echelle d'autoévaluation. European-Psychiatry, 4(3), 163-166.

Geva, S., Bennett, S., Warburton, E. A., \& Patterson, K. (2011). Discrepancy between inner and overt speech: Implications for post-stroke aphasia and normal language processing. Aphasiology, 25(3), 323-343. http://doi.org/10.1080/02687038.2010.511236

Goldwin, M., \& Behar, E. (2012). Concreteness of Idiographic Periods of Worry and Depressive Rumination. Cognitive Therapy and Research, 36, 840-846. http://doi.org/10.1007/s10608011-9428-1

Grèzes, J., \& Decety, J. (2001). Functional anatomy of execution, mental simulation, observation, and verb generation of actions: A meta-analysis. Human Brain Mapping, 12(1), 1-19.

Huffziger, S., Ebner-Priemer, U., Koudela, S., Reinhard, I., \& Kuehner, C. (2012). Induced rumination in everyday life: Advancing research approaches to study rumination. $\begin{array}{llll}\text { Personality and } \quad \text { Individual } & \text { 790-795. }\end{array}$ http://doi.org/10.1016/j.paid.2012.06.009

Jacobson, E. (1931). Electrical measurements of neuromuscular states during mental activities: VII. Imagination, recollection, and abstract thinking involving the speech musculature. American Journal of Physiology, 97, 200-209. 
839

840

841

842

843

844

845

846

847

848

849

850

851

852

853

854

855

856

857

858

859

860

861

862

863

864

865

866

867

868

869

870

871

872

873

874

875

876

877

878

879

880

881

Jäncke, L. (1996). Facial EMG in an anger-provoking situation: Individual differences in directing anger outwards or inwards. International Journal of Psychophysiology, 23(3), 207-214. http://doi.org/10.1016/s0167-8760(96)00062-1

Jäncke, L., Vogt, J., Musial, F., Lutz, K., \& Kalveram, K. T. (1996). Facial EMG responses to auditory stimuli. International Journal of Psychophysiology, 22, 85-96. http://doi.org/10.1016/0167-8760(96)00013-x

Johnson, D. P., \& Whisman, M. (2013). Gender differences in rumination: A meta-analysis. Personality and Individual Differences, 55(4), 367-374. http://doi.org/10.1016/j.paid.2013.03.019

Jones, S. R., \& Fernyhough, C. (2007). Thought as action: Inner speech, self-monitoring, and auditory verbal hallucinations. Consciousness and Cognition, 16(2), 391-399. http://doi.org/10.1016/j.concog.2005.12.003

Key, B. L., Campbell, T. S., Bacon, S. L., \& Gerin, W. (2008). The influence of trait and state rumination on cardiovascular recovery from a negative emotional stressor. Journal of Behavioral Medicine, 31(3), 237-248. http://doi.org/10.1007/s10865-008-9152-9

Kohler, C. G., Turner, T., Stolar, N., Bilker, W., Brensinger, C., Gur, R. E., \& Gur, R. C. (2004). Differences in facial expression of four universal emotions. Psychiatry Research, 128(3), 235-244. http://doi.org/10.1016/j.psychres.2004.07.003

Landauer, T. K. (1962). Rate of implicit speech. Perceptual and Motor Skills, 15(7), 646. http://doi.org/10.2466/pms.15.7.646-646

Langland-Hassan, P., Faries, F. R., Richardson, M. J., \& Dietz, A. (2015). Inner speech deficits in people with aphasia. Frontiers in Psychology, 6, 1-10. http://doi.org/10.3389/fpsyg.2015.00528

LeMoult, J., \& Joormann, J. (2014). Depressive rumination alters cortisol decline in Major Depressive Disorder. Biological Psychology, 100, 50-55. http://doi.org/10.1016/j.biopsycho.2014.05.001

Levine, D. N., Calvanio, R., \& Popovics, A. (1982). Language in the absence of inner speech. Neuropsychologia, 20(4), 391-409. https://doi.org/10.1016/0028-3932(82)90039-2

Livesay, J., Liebke, A., Samaras, M., \& Stanley, A. (1996). Covert speech behavior during a silent language recitation task. Perception and Motor Skills, 83, 1355-1362. http://doi.org/10.2466/pms.1996.83.3f.1355

MacKay, D. G. (1992). Constraints on theories of inner speech. In D. Reisberg (Ed.), Auditory Imagery (pp. 121-49). NJ/England: Erlbaum.

Marshall, R., Rappaport, B., \& Garcia-Bunuel, L. (1985). Self-monitoring behavior in a case of severe auditory agnosia with aphasia. Brain and Language, 24(2), 297-313.

Martin, R. C., \& Caramazza, A. (1982). Short-term memory performance in the absence of phonological coding. Brain and Cognition, 1(1), 50-70. http://doi.org/10.1016/02782626(82)90006-9

McGuigan, F. J., \& Dollins, A. B. (1989). Patterns of covert speech behavior and phonetic coding. Pavlovian Journal of Biological Science, 24, 19-26.

McLaughlin, K. A., Borkovec, T. D., \& Sibrava, N. J. (2007). The effects of worry and rumination on affect states and cognitive activity. Behavior Therapy, 38(3), 23-38. http://doi.org/10.1016/j.beth.2006.03.003 
882

883

884

885

886

887

888

889

890

891

892

893

894

895

896

897

898

899

900

901

902

903

904

905

906

907

908

909

910

911

912

913

914

915

916

917

918

919

920

921

922

923

924

925

Morey, R. D., Hoekstra, R., Rouder, J. N., Lee, M. D., \& Wagenmakers, E.-J. (2015). The fallacy of placing confidence in confidence intervals. Psychonomic Bulletin \& Review, 23, 103-123. http://doi.org/10.3758/s13423-015-0947-8

Netsell, R., Ashley, E., \& Bakker, K. (2010). The inner speech of persons who stutter. In: Proceedings of the international motor speech conference.

Nisbett, J., \& Wilson, T. D. (1977). Telling more than we can know: Verbal reports of mental processes. Psychological Review, 84(3), 231-259. http://doi.org/10.1037//0033$295 \times .84 .3 .231$

Nolen-Hoeksema, S. (1991). Responses to depression and their effects on the duration of depressive episodes. Journal of Abnormal Psychology, 100(4), 569-582. http://doi.org/10.1037//0021-843x.100.4.569

Nolen-Hoeksema, S., \& Morrow, J. (1991). A prospective study of depression and posttraumatic stress symptoms after a natural disaster: the 1989 Loma Prieta Earthquake. Journal of Personality and Social Psychology, 61(1), 115-121. http://doi.org/10.1037//00223514.61.1.115

Nolen-Hoeksema, S., \& Morrow, J. (1993). Effects of rumination and distraction on naturally occurring depressed mood. Cognition and Emotion, 7(6), 561-570. http://doi.org/10.1080/02699939308409206

Nolen-Hoeksema, S., Wisco, B. E., \& Lyubomirsky, S. (2008). Rethinking Rumination. Perspectives on Psychological Science, 3(5), 400-424. http://doi.org/10.1111/j.17456924.2008.00088.x

Oppenheim, G. M., \& Dell, G. S. (2010). Motor movement matters: the flexible abstractness of inner speech. Memory and Cognition, 38(8), 1147-1160. http://doi.org/10.3758/mc.38.8.1147

Ottaviani, C., Thayer, J. F., Verkuil, B., Lonigro, A., Medea, B., Couyoumdjian, A., Brosschot, J. F. (2015). Physiological concomitants of perseverative cognition: A systematic review and meta-analysis. Psychological Bulletin, 142(3), 231-259. http:// dx.doi.org/10.1037/bul0000036

Palmer, E. D., Rosen, H. J., Ojemann, J. G., Buckner, R. L., Kelley, W. M., \& Petersen, S. E. (2001). An event-related fMRI study of overt and covert word stem completion. Neuroimage, 14(1), 182-193. http://doi.org/10.1006/nimg.2001.0779

Paulesu, E., Frith, C. D., \& Frackowiak, R. S. J. (1993). The neural correlates of the verbal components of working memory. Nature, 362(6418), 342-345. http://doi.org/10.1038/362342a0

Penney, A., Miedema, V., Mazmanian, D. (2015). Intelligence and emotional disorders: Is the worrying and ruminating mind a more intelligent mind? Personality and Individual Differences, 74, 90-93. http://doi.org/10.1016/j.paid.2014.10.005

Perrone-Bertolotti, M., Rapin, L., Lachaux, J. P., Baciu, M., \& Lœvenbruck, H. (2014). What is that little voice inside my head? Inner speech phenomenology, its role in cognitive performance, and its relation to self-monitoring. Behavioural Brain Research, 261, 220239. http://doi.org/10.1016/j.bbr.2013.12.034

Postma, A., \& Noordanus, C. (1996). The production and detection of speech errors in silent, mouthed, noise- masked, and normal auditory feedback speech. Language and Speech, 39, 375-392. 
926

927

928

929

930

931

932

933

934

935

936

937

938

939

940

941

942

943

944

945

946

947

948

949

950

951

952

953

954

955

956

957

958

959

960

961

962

963

964

965

966

967

968

969

Rapin, L., Dohen, M., Polosan, M., Perrier, P., \& Lœvenbruck, H. (2013). An EMG study of the lip muscles during covert auditory verbal hallucinations in schizophrenia. Journal of Speech, Language, and Hearing Research, 56(6), 1882-1893. http://doi.org/10.1044/10924388(2013/12-0210)

Regalo, S. C. H., Vitti, M., Moraes, M. T. B., Semprini, M., Felacio, C. M. D., Mattos, M. D. G. C. D., ... \& Santos, C. M. (2005). Electromyographic analysis of the orbicularis oris muscle in oralized deaf individuals. Brazilian Dental Journal, 16(3), 237-242. http://doi.org/10.1590/s0103-64402005000300012

Rippere, V. (1977). What's the thing to do when you're feeling depressed? A cross-cultural replication. Behaviour Research and Therapy, 15(2), 185-191. http://doi.org/10.1016/00057967(77)90104-8

Robinson, M., \& Alloy, L. (2003). Negative cognitive styles and stress-reactive rumination interact to predict depression: A prospective study. Cognitive Therapy and Research, 27(3), 275-292.

Rood, L., Roelofs, J., Bögels, S. M., \& Arntz, A. (2012). The effects of experimentally induced rumination, positive reappraisal, acceptance, and distancing when thinking about a stressful event on affect states in adolescents. Journal of Abnormal Child Psychology, 40(1), 73-84. http://doi.org/10.1007/s10802-011-9544-0

RStudio Team (2015). RStudio: Integrated Development for R. RStudio, Inc., Boston, MA URL http://www.rstudio.com/.

Salahuddin, L., Cho, J., Jeong, M. G., \& Kim, D. (2007). Ultra short term analysis of heart rate variability for monitoring mental stress in mobile settings. Conference Proceedings: $29^{\text {th }}$ Annual International Conference of the IEEE Engineering in Medicine and Biology Society. IEEE Engineering in Medicine and Biology Society, 4656-4659.

Shuster, L. I., \& Lemieux, S. K. (2005). An fMRI investigation of covertly and overtly produced mono- and multisyllabic words. Brain and Language, 93(1), 20-31. http://doi.org/10.1016/j.bandl.2004.07.007

Siegle, G. J., \& Thayer, J. F. (2003). Physiological aspects of depressive rumination. In: Papageorgiou C, Wells A, (Eds.). Depressive rumination: nature, theory and treatment. New York: Wiley. http://doi.org/10.1002/9780470713853.ch5

Sigmon, S. T., Dorhofer, D. M., Rohan, K. J., \& Boulard, N. E. (2000). The impact of anxiety, sensitivity, bodily expectations, and cultural beliefs on menstrual symptom reporting: A test of the menstrual reactivity hypothesis. Journal of Anxiety Disorders, 14(6), 615-633. http://doi.org/10.1016/s0887-6185(00)00054-2

Sokolov, A. N. (1972). Inner speech and thought (G.T. Onischenko, Trans.). New York: Plenum Press. http://doi.org/10.1007/978-1-4684-1914-6

Sumitsuji, N., Matsumoto, K., Tanaka, M., Kashiwagi, T., \& Kaneko, Z. (1967). Electromyographic investigation of the facial muscles. Electromyography, 7(2), 77-96.

Tassinary, L. G., Cacioppo, J. T., \& Vanman, E. J. (2007). The skeletomotor system: Surface electromyography. In J. T. Cacioppo, L. G. Tassinary, \& G. G. Berntson (Eds.), Handbook of psycho- physiology (3rd ed., pp. 267-297). Cambridge, England: Cambridge University Press. http://doi.org/10.1017/cbo9780511546396.012

Treynor, W., Gonzalez, R., \& Nolen-Hoeksema, S. (2003). Rumination reconsidered: A psychometric analysis. Cognitive Therapy and Research, 27, 247-259. 
Uttl, B., Morin, A., \& Hamper, B. (2011). Are inner speech self-report questionnaires reliable and valid? Social and Behavioral Sciences, 30, 1719-1723. http://doi.org/10.1016/j.sbspro.2011.10.332

Vallar, G., \& Cappa, S. F. (1987). Articulation and verbal short-term memory: Evidence from anarthria. $\quad$ Cognitive Neuropsychology; $\quad 4(1), \quad 55-77$. http://doi.org/10.1080/02643298708252035

Van Boxtel, A. (2001). Optimal signal bandwidth for the recording of surface EMG activity of facial, jaw, oral, and neck muscles. Psychophysiology, 38(1), 23-34. http://doi.org/10.1111/1469-8986.3810022

Van Boxtel, A., \& Jessurun, M. (1993). Amplitude and bilateral coherency of facial and jawelevator EMG activity as an index of effort during a two-choice serial reaction task. Psychophysiology, 30(6), 589-604. http://doi.org/10.1111/j.1469-8986.1993.tb02085.x

Van Randenborgh, A., Hüffmeier, J., LeMoult, J., \& Joormann, J. (2010). Letting go of unmet goals: Does self- focused rumination impair goal disengagement? Motivation and Emotion, 34(4), 325-332. http://doi.org/10.1007/s11031-010-9190-9

Vickers, K. S., \& Vogeltanz-Holm, N. D. (2003). The effects of rumination and distraction tasks on psychophysiological responses and mood in dysphoric and nondysphoric individuals. Cognitive Therapy and Research, 27, 331-348.

Vygotsky, L. S. (1987). LS Vygotsky, Collected works Vol. I (R. Rieber \& A. Carton, Eds; N. Minick, Trans.).

Watanabe, S. (2010). Asymptotic equivalence of Bayes cross validation and widely applicable information criterion in singular learning theory. Journal of Machine Learning Research, $11,3571-3594$.

Watkins, E. R. (2004). Adaptive and maladaptive ruminative self-focus during emotional processing. Behaviour Research and Therapy, 42(9), 1037-1052. http://doi.org/10.1016/j.brat.2004.01.009

Watkins, E. R. (2008). Constructive and unconstructive repetitive thought. Psychological Bulletin, 134(2), 163-206. http://doi.org/10.1037/0033-2909.134.2.163

Woody, M. L., McGeary, J. E., \& Gibb, B. E. (2014). Brooding rumination and heart rate variability in women at high and low risk for depression: Group differences and moderation by COMT genotype. Journal of Abnormal Psychology, 123(1), 61-67. http://dx.doi.org/10.1037/ a0035450

1002 Zivin, G. (1979). The development of self-regulation through private speech. New York: Wiley. 